\title{
Activation of Acyclic and Cyclic Conjugated Dienes in Cooperation with the Three Metal Centers
}

\author{
Hiroharu Suzuki, Toshifumi Takemori, and Akiko Inagaki \\ Department of Applied Chemistry, Graduate School of Science and Engineering, \\ Tokyo Institute of Technology and CREST, Japan Science and Technology Corporation (JST),
}

\begin{abstract}
Trinuclear ruthenium pentahydride complex $\left(C p{ }^{\prime} R u\right)_{3}(\mu-H)_{3}\left(\mu_{3}-H\right)_{2}\left(1: C p^{\prime}=\right.$ $\left.\eta^{5}-C_{5} M_{5}\right)$ reacts with a series of acyclic conjugated dienes such as butadiene, isoprene, or penta-1,3-diene to form trinuclear $\mu_{3}-1,3$-dimetalloallyl complexes 2 by way of an intermediary $\mu_{3}-\eta^{2}: \eta^{2}-s-c i s-1,3-d i e n e$ complex. In the reactions with butadiene and isoprene, an agostic intermediate, in which three ruthenium centers concertedly activate a 1,3-diene by taking the role of coordination sites and an activation site, is detected by ${ }^{1} \mathrm{H}$ and ${ }^{13} \mathrm{C} N M R$. The intermediary 1,3-diene complexes with agostic interaction undergo $C\left(s p^{2}\right)$-H bond cleavage at room temperature to generate 1,3-dimetalloallyl complexes. The reaction of 1 with cyclopentadiene generates a trinuclear $\mu_{3}-2$-methylruthenacyclopentadiene complex 4 as a result of cleavage of the unactivated $C\left(s p^{3}\right)-C\left(s p^{2}\right)$ bond. In the reaction of 1 with 1,3-cyclohexadiene, cleavage of an allylic $C$ - $H$ bond followed by the $\beta$-H elimination affords a $\mu_{3}-\eta^{2}: \eta^{2}: \eta^{2}$-benzene complex.
\end{abstract}

\section{Introduction}

Transition metal cluster complexes have been of special interest in terms of their reactivities in the area of recent organometallic chemistry because of their capability of multiple-coordination of substrate and multi-electron transfer between the substrate and the cluster. On the multimetallic reaction site provided by the cluster complex, substrates would be, thus, activated in an effective and somewhat different manner from that observed on the reaction site of a mononuclear complex due to the cooperative action of the metal centers. It has been well established that the mononuclear polyhydride complex gives rise to a coordinatively unsaturated site upon thermal excitation, UV irradiation, or hydrogen transfer to an olefin (ref. 1). The multinuclear polyhydride complex can, therefore, be considered as a suitable precursor for multimetallic activation that is a distinctive manner of substrate activation achieved by the concerted action of many metal centers. As part of our early efforts directed toward preparing multinuclear polyhydride complexes, we reported the synthesis and reactions of a dinuclear tetrahydride-bridged complex of ruthenium, $(\mathrm{Cp} \cdot \mathrm{Ru})_{2}(\mu-\mathrm{H})_{4}$, 
which readily generated unsaturated sites on the same side of the molecular plane upon heating or treatment with a hydrogen acceptor. We have demonstrated several typical examples of the bimetallic activation by using $\left(\mathrm{Cp}^{\prime} \mathrm{Ru}\right\}_{2}(\mu-\mathrm{H})_{4}$ as a precursor of the active species (ref. 2). As an extension of bimetallic activation, we focused our attention on activation of substrates on trimetallic systems. As mentioned above, a trinuclear polyhydride-bridged complex $\left(\mathrm{Cp}^{\prime} \mathrm{Ru}\right)_{3}(\mu-\mathrm{H})_{3}\left(\mu_{3}-\mathrm{H}\right)_{2}(\mathbf{1})$ must be a suitable precursor for the trimetallic activation because it possibly gives rise to unsaturated sites on each of the metal centers (ref. 3). The triangular framework of $\mathbf{1}$ is tightly bound by five bridging hydrides. Compound 1 is indeed very stable and does not break up into a mononuclear or dinuclear species at any significant rate even in refluxing $o$-xylene. It is one of the key features of 1 that a carbonyl ligand is not included in 1, neither as a bridging nor a terminal carbonyl. Electron density at the metal centers of $\mathbf{1}$ is, therefore, higher than that of the polyhydoridometal clusters having carbonyl ligands due to coordination of the electron-releasing $\mathrm{C}_{5} \mathrm{Me}_{5}$ groups instead of electron-withdrawing carbonyl ligands. Thus, complex $\mathbf{1}$ is expected to be much more active than the polycarbonylhydoridometal cluster towards oxidative addition of both $\mathrm{C}-\mathrm{H}$ and $\mathrm{C}-\mathrm{C}$ bonds. Moreover, a triangular empty space surrounded by the three $\mathrm{C}_{5} \mathrm{Me}_{5}$ rings can become a reaction site in which substrates are taken in and activated in a shapeselective manner due to the steric repulsion among substrates and the $\mathrm{C}_{5} \mathrm{Me}_{5}$ groups.

We describe herein activation of acyclic and cyclic conjugated dienes on the trimetallic reaction site of $(\mathrm{Cp} \cdot \mathrm{Ru})_{3}(\mu-\mathrm{H})_{3}\left(\mu_{3}-\mathrm{H}\right)_{2}(\mathbf{1})$.

2. Reaction of 1 with Acyclic Conjugated Diene. Formation of Novel Trinuclear $\mu_{3}-\eta^{2}: \eta^{2}-s-$ cis-1,3-diene Complexes of Ruthenium Having an Agostic Ru-H-C Interaction.

Treatment of 1 with excess butadiene (1 atm) in tetrahydrofuran at room temperature for $12 \mathrm{~h}$ led to the formation of a trinuclear 1-methyl-1,3-dimetalloallyl complex $(\mathrm{Cp} ' \mathrm{Ru})(\mathrm{H})_{4}\left\{\mu_{3}-\eta^{3}-\right.$ $\mathrm{C}(\mathrm{Me}) \mathrm{CHCH}$ \} (2a), which was isolated in $70 \%$ yield as dark-green crystalline solids. The reaction of 1 with isoprene proceeded in a similar manner at ambient temperature to form the corresponding $\mu_{3}$-dimetalloallyl complex $\mathbf{2 b}$ (eq. 1).

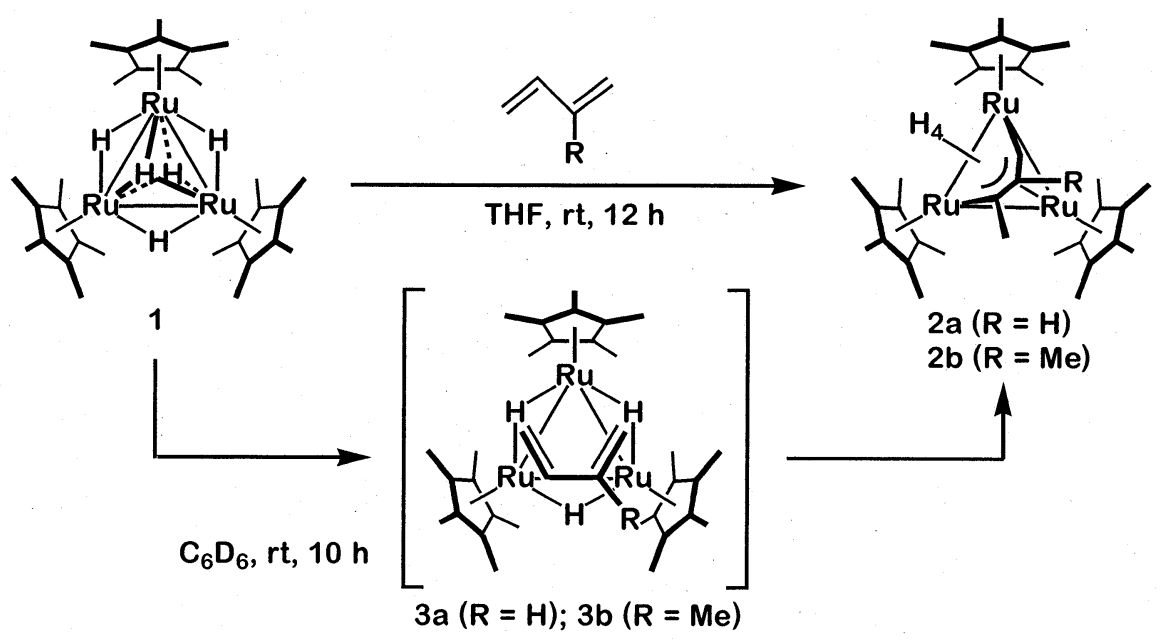

(eq. 1) 
The molecular structure of 2a was definitely proven by X-ray crystallography and is illustrated in Figure 1. The allyl skeleton is disordered between two orientations (64:36).

Monitoring the reaction of 1 with 1 equiv of isoprene in benzene- $d_{6}$ at room temperature by ${ }^{1} \mathrm{H}$ and ${ }^{13} \mathrm{C}$ NMR spectrometry showed the formation of an intermediary trinuclear $\mu-\eta^{2}: \eta^{2}-s$-cis-isoprene complex $\mathbf{3 b}$ in the initial stage of the reaction, which involved agostic interaction among the terminal carbon and hydrogen atoms and one of the ruthenium atoms. The ${ }^{1} \mathrm{H}$ NMR spectrum of $\mathbf{3 b}$ displayed a singlet at $\delta 1.18(3 \mathrm{H})$ and five multiplet resonances at $\delta-9.33(1 \mathrm{H}), 0.59(1 \mathrm{H}), 1.26(1 \mathrm{H})$, $1.54(1 \mathrm{H})$, and $3.91(1 \mathrm{H})$ assignable to the methyl group, four methylene protons, and a methine

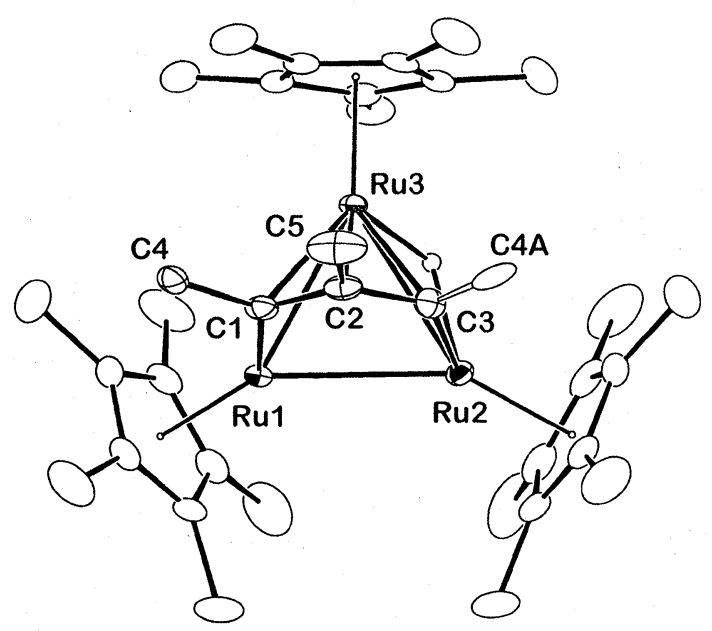

Figure 1. ORTEP drawing of 2a proton, respectively, of the coordinated isoprene. The ${ }^{13} \mathrm{C}$ resonances for the isoprene in $\mathbf{3 b}$ underwent substantial upfield shifts as a result of coordination. The assignment of these resonances is shown in Chart 1.

Chart 1

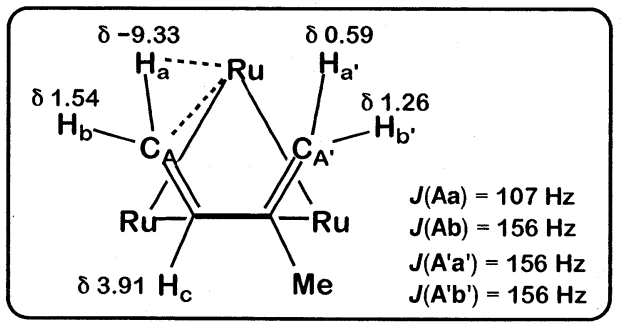

Chart 2

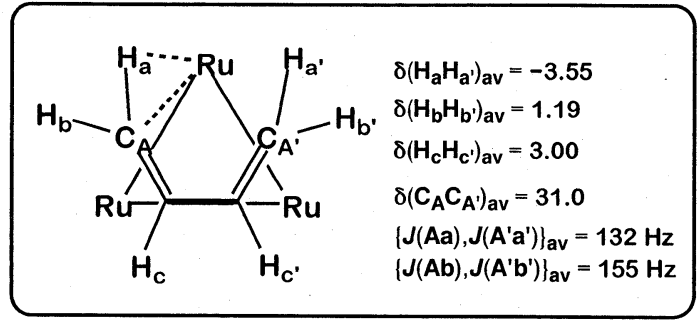

Notable features of the NMR spectra are the resonances appearing at $\delta 44.2\left(J_{\mathrm{CH}}=156\right.$ and 107 $\mathrm{Hz}$ ) in the ${ }^{13} \mathrm{C}$ NMR spectrum and that observed at $\delta-9.33$ in the ${ }^{1} \mathrm{H}$ NMR spectrum. The small $\mathrm{C}\left(s p^{2}\right)-\mathrm{H}$ coupling constant $\left(J_{\mathrm{CH}}=107 \mathrm{~Hz}\right)$ and the upfield shift $(\delta-9.33)$ of the resonance for the terminal methylene proton to the hydride region unambiguously indicates the presence of three-center two-electron $\mathrm{Ru}-\mathrm{H}-\mathrm{C}$ interaction (ref. 4).

An intermediary agostic complex 3a was similarly detected in the reaction of $\mathbf{1}$ with butadiene by means of NMR spectroscopy. The reaction of 1 with 1.5 equiv of butadiene in toluene- $d_{8}$ for 5 $\mathrm{min}$ at $243 \mathrm{~K}$ brought about the complete consumption of $\mathbf{1}$ to give a $95 / 5$ mixture of $\mathbf{3 a}$ and $\mathbf{2 a}$. The ${ }^{1} \mathrm{H}$ resonances attributable to the intermediate $3 \mathrm{a}$ consisted of three multiplets at $\delta-3.55(2 \mathrm{H}), 1.19$ $(2 \mathrm{H})$, and $3.00(2 \mathrm{H})$ for the coordinated butadiene besides two singlets for the $\mathrm{C}_{5} \mathrm{Me}_{5}$ groups and two hydride signals at $\delta 1.72(30 \mathrm{H}), 1.79(15 \mathrm{H}),-21.79(2 \mathrm{H})$, and $-16.44(2 \mathrm{H})$, respectively. The ${ }^{13} \mathrm{C}$ NMR spectrum for the mixture exhibited two resonances for the butadiene coordinated in $\mathbf{3 a}$ at $\delta 31.0$ 
$\left(\mathrm{dd}, J_{\mathrm{CH}}=154.7\right.$ and $\left.131.9 \mathrm{~Hz}\right)$ and $49.3\left(\mathrm{~d}, J_{\mathrm{CH}}=151.1 \mathrm{~Hz}\right)$. The assignment of these resonances is shown in Chart 2.

The $\delta$ value of $-3.55 \mathrm{ppm}$ for the methylene proton of the butadiene ligand in $3 \mathbf{a}(\delta-3.55)$ is close to the average value of the shifts for the methylene protons, $\delta-9.33$ and 0.59 in $\mathbf{3 b}$. In addition, the $J_{\mathrm{CH}}$ value of $131.9 \mathrm{~Hz}$ is very close to the averaged value of those for the agostic $\mathrm{C}\left(s p^{2}\right)-\mathrm{H}(J=$ $107.0 \mathrm{~Hz})$ and non-agostic $\mathrm{C}\left(s p^{2}\right)-\mathrm{H}(J=156.0 \mathrm{~Hz})$ bonds observed for $\mathbf{3 b}$. These findings strongly indicate that complex $\mathbf{3 a}$ is a fluxional agostic complex. The dynamic process was so rapid that the ${ }^{1} \mathrm{H}$ NMR spectrum measured at $190 \mathrm{~K}$ was essentially the same as that measured at $243 \mathrm{~K}$.

The intermediates $\mathbf{3 a}$ and $\mathbf{3 b}$ undergo activation of the agostic $\mathrm{C}-\mathrm{H}$ bond to ultimately form the 1,3-dimetalloallyl complexes $\mathbf{2 a}$ and $\mathbf{2} \mathbf{b}$, respectively. These results show that two of the three ruthenium centers in $\mathbf{1}$ act as coordination sites and the third metal takes the role of an activation site via the agostic interaction in the reaction with 1,3-diene. This is a typical example showing the activation process performed by the concerted action of the three metal centers.

Formation of the $\mu_{3}-\eta^{2}: \eta^{2}-s-c i s-1,3-$ diene complexes $\mathbf{3 a}$ and $\mathbf{3 b}$ suggests the mechanism shown in Scheme 1 for the reaction of $\mathbf{1}$ with acyclic conjugated dienes leading to the exclusive formation of the $\mu_{3}-1,3$-dimetalloallyl complexes. Upon incorporation of the 1,3-diene into the triangular reaction site, the diene ligand is forced to adopt the $s$-cis conformation to minimize the steric repulsion between the substrate and the $\mathrm{C}_{5} \mathrm{Me}_{5}$ groups. The agostic intermediate undergoes activation of a carbon-hydrogen bond to form a $\mu_{3}-\eta^{1}: \eta^{2}: \eta^{2}$-dienyl complex. Insertion of the terminal cabon-carbon double bond into an adjacent $\mathrm{Ru}-\mathrm{H}$ bond followed by carbon-hydrogen cleavage at the allylic position of the resulting dimetallocyclopentene gave the $\mu_{3}-1,3$-dimetalloallyl complex as a final product.

\section{Scheme 1}

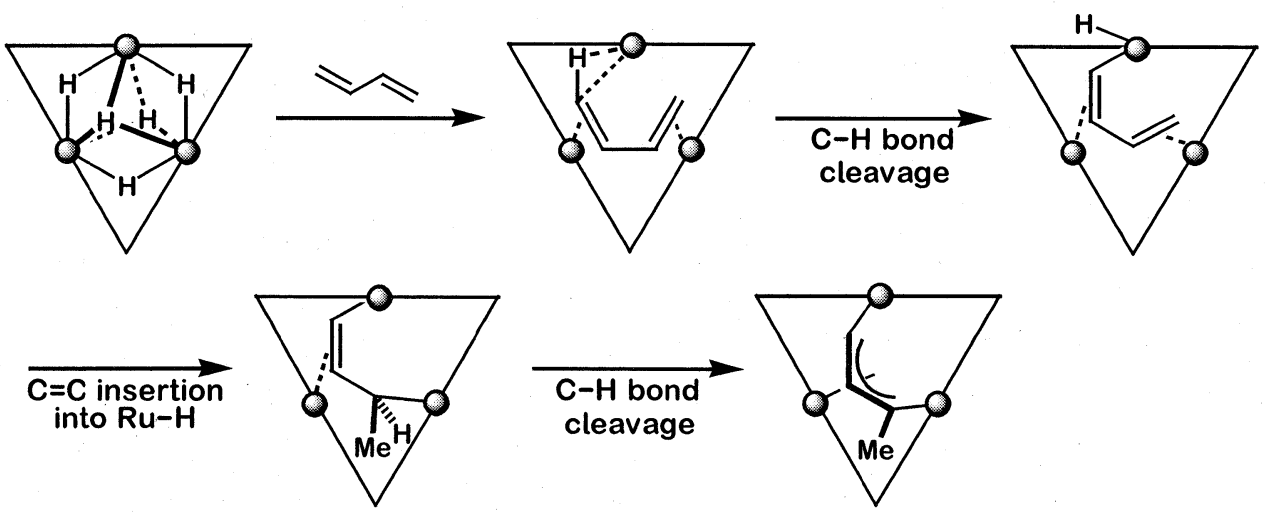

The trimetallic reaction site of $\mathbf{1}$ is surrounded by the three $\mathrm{C}_{5} \mathrm{Me}_{5}$ groups and steric repulsion between the $\mathrm{C}_{5} \mathrm{Me}_{5}$ ligand and the substrate strongly influences the incorporation step of the substrate into the trimetallic site. As a result, remarkable shapeselectivity for the incorporation of the substrate was observed in the reaction of 1 with a series of substituted 1,3-dienes. While complex 1 readily reacted with monosubstituted 1,3-butadienes such as isoprene, 1,3-pentadiene, and 1,3- 
hexadiene to generate the corresponding $\mu_{3}-1,3$-dimetalloallyl complexes exclusively, the reaction of 1 with disubstituted butadienes such as 2,3-dimethyl-1,3-butadiene, 2-methyl-1,3-pentadiene, 3methyl-1,3-pentadiene, and 2,4-hexadiene resulted in the recovery of the starting complex 1 and the diene (Chart 3).

\section{Chart 3}

Dienes accessible to the reaction sites

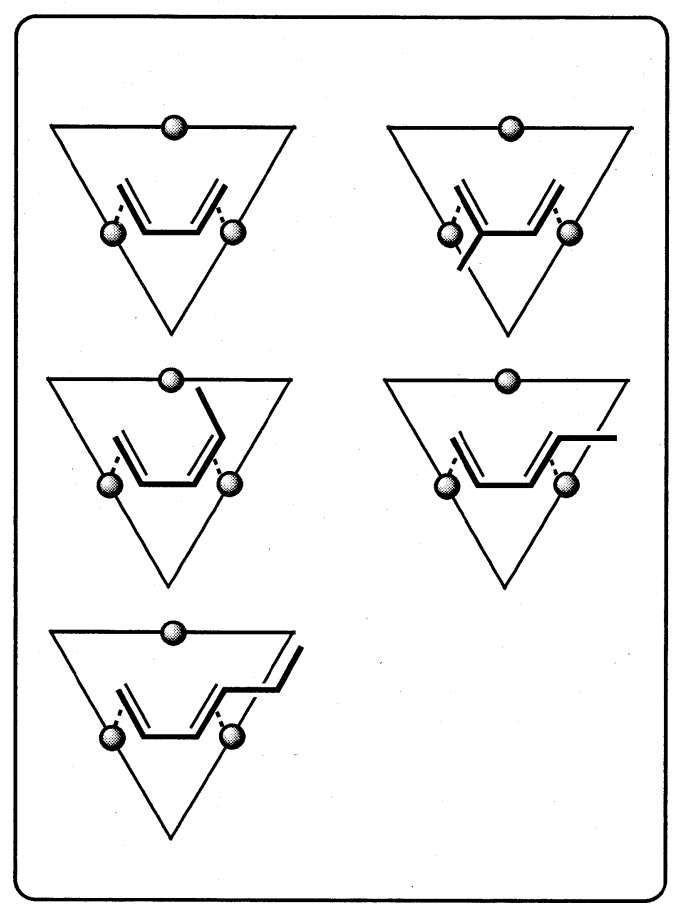

\section{Dienes with serious steric hindrance}

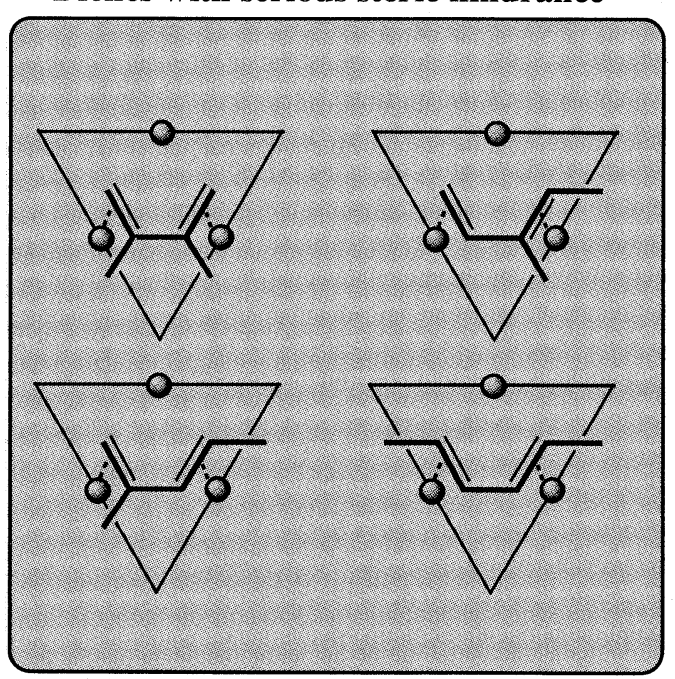

3. Reaction of 1 with Cyclopentadiene. Selective Carbon-carbon Bond Cleavage in Cooperation with the Three Metal Centers.

A new mode of substrate activation, multimetallic activation, that was characteristic of the cluster complexes was also observed in the reaction of $\mathbf{1}$ with cyclopentadiene. The reaction of $\mathbf{1}$ with 5 equiv of cyclopentadiene in tetrahydrofuran at room temperature for $12 \mathrm{~h}$ leads to the quantitative formation of the trinuclear 2-methylruthenacyclopentadiene $(\mathrm{Cp} \cdot \mathrm{Ru})_{3}(\mu-\mathrm{H})_{3}\left\{\mu_{3}-\eta^{4}-\right.$ $\mathrm{C}(\mathrm{Me})=\mathrm{CHCH}=\mathrm{CH}\}(4)$ as a result of the $\mathrm{C}\left(s p^{2}\right)-\mathrm{C}\left(s p^{3}\right)$ bond cleavage of the cyclopentadiene (eq. 2). To our knowledge, this is the first example of the selective activation of an unactivated carbon-carbon bond in cooperation with the three metal centers. The kinetic parameters of $\Delta \mathrm{H}^{\ddagger}=12.7(3) \mathrm{kcal} \mathrm{mol}^{-}$ ${ }^{1}$ and $\Delta \mathrm{S}^{\dagger}=-30.0(10) \mathrm{cal} \mathrm{mol}^{-1} \mathrm{~K}^{-1}$ for this reaction indicate that incorporation of the cyclopentadiene into the trimetallic reaction site is the rate-determining step. 


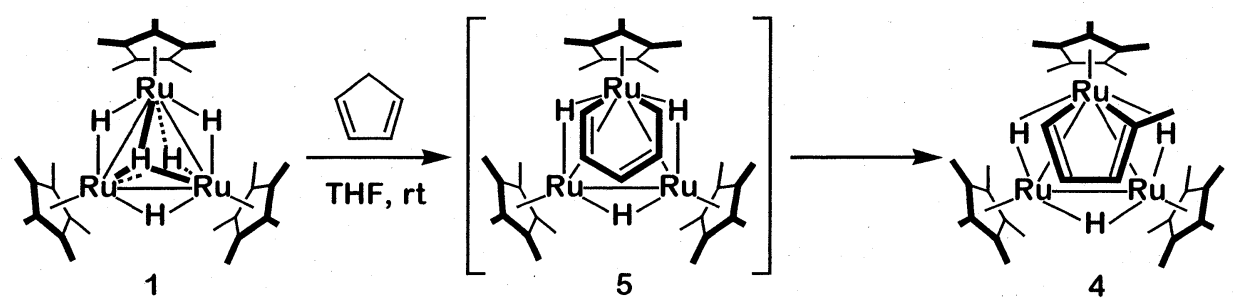

(eq. 2)

Complex 4 was characterized on the basis of the ${ }^{1} \mathrm{H}$ and ${ }^{13} \mathrm{C}$ NMR spectra as well as the ${ }^{1} \mathrm{H}-{ }^{1} \mathrm{H}$ COSY and ${ }^{1} \mathrm{H}-{ }^{13} \mathrm{C}$ HSC spectra and definitive proof of the structure of 4 was provided by X-ray crystallography (Fig. 2).

Monitoring the reaction of 1 with 5 equiv of cyclopentadiene in tetrahydrofuran- $d_{8}$ at room temperature by ${ }^{1} \mathrm{H}$ NMR spectrometry showed the formation of an intermediary ruthenacyclohexadiene $\mathbf{5}$ in the initial stage of the reaction. Although 5 could not be isolated, it was unambiguously characterized by means of NMR spectrometry.

To elucidate the reaction mechanism, labeling experiment was performed by use of triruthenium pentadeuteride complex $1-d_{5}$. The reaction of $1-d_{5}$

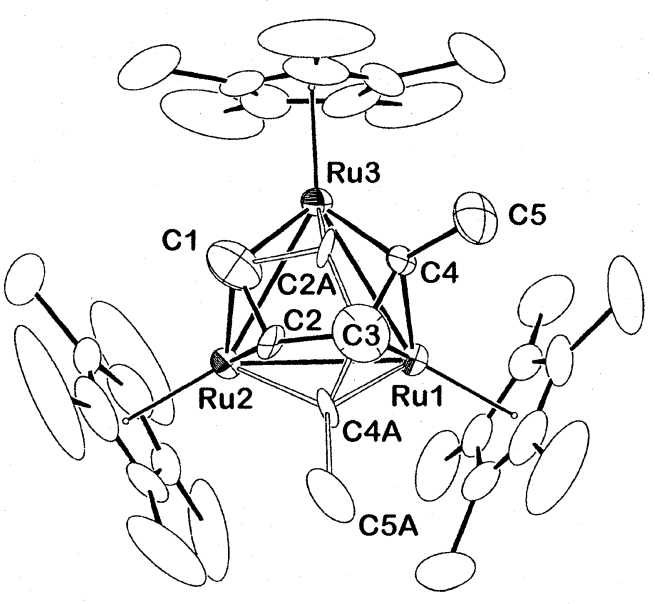

Figure 2. ORTEP drawing of 4 with cyclopentadiene- $h_{6}$ smoothly proceeded at room temperature to give an isotopomer of the 2methylruthenacyclopentadiene $4-d_{\mathrm{n}}$ in which the deuterides were uniformly scrambled over the ruthenacycle (eq. 3). This result indicates that the activation of the carbon-hydrogen bond at the allylic position of cyclopentadiene leading a $\mu_{3}$-cyclopentadienyl intermediate takes place prior to the carbon-carbon bond cleavage.

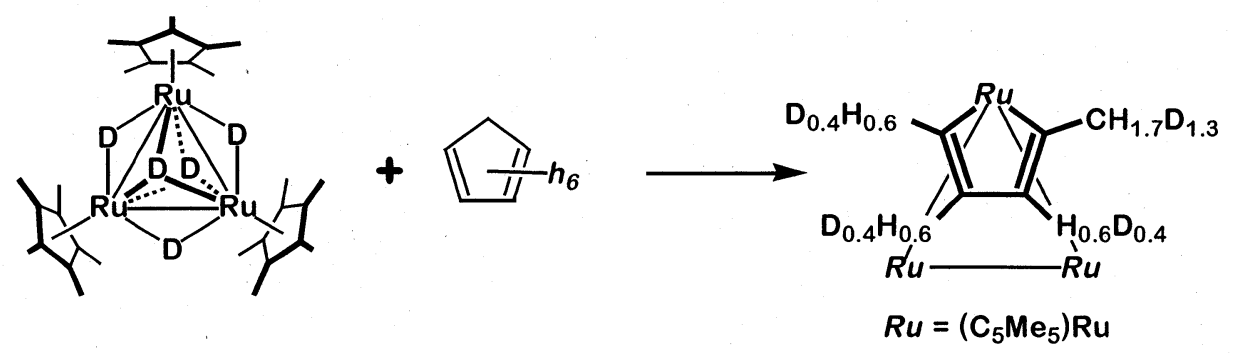


One plausible reaction mechanism involving a pre-equilibrium between a $\mu_{3}-\eta^{2}: \eta^{2}$ cyclopentadiene complex and a $\mu_{3}-\eta^{5}$-cyclopentadienyl complex is illustrated in Scheme 2 . Cyclopentadiene incorporated into the $\mathrm{Ru}_{3}$ core is bound to two of the three ruthenium centers in 1 through $\mu-\eta^{2}: \eta^{2}$ coordination to form the $\mu_{3}$-cyclopentadiene complex. In the intermediary $\mu_{3}-$ cyclopentadiene complex, both the allylic $\mathrm{C}-\mathrm{H}$ bond and the $\mathrm{C}\left(s p^{3}\right)-\mathrm{C}\left(s p^{2}\right)$ bond are nicely oriented towards the third metal for the bond cleavage. Ruthenacyclohexadiene formed as a result of the $\mathrm{C}\left(s p^{3}\right)$-C $\left(s p^{2}\right)$ bond cleavage is in equilibrium with a $\mu_{3}$-penta-1,4-dien-1,3-diyl complex, which undergoes insertion of a carbon-carbon double bond into $\mathrm{Ru}-\mathrm{H}$ to yield a $\mu_{3}-5$ methylruthenecyclopent-2-ene complex.

Scheme 2
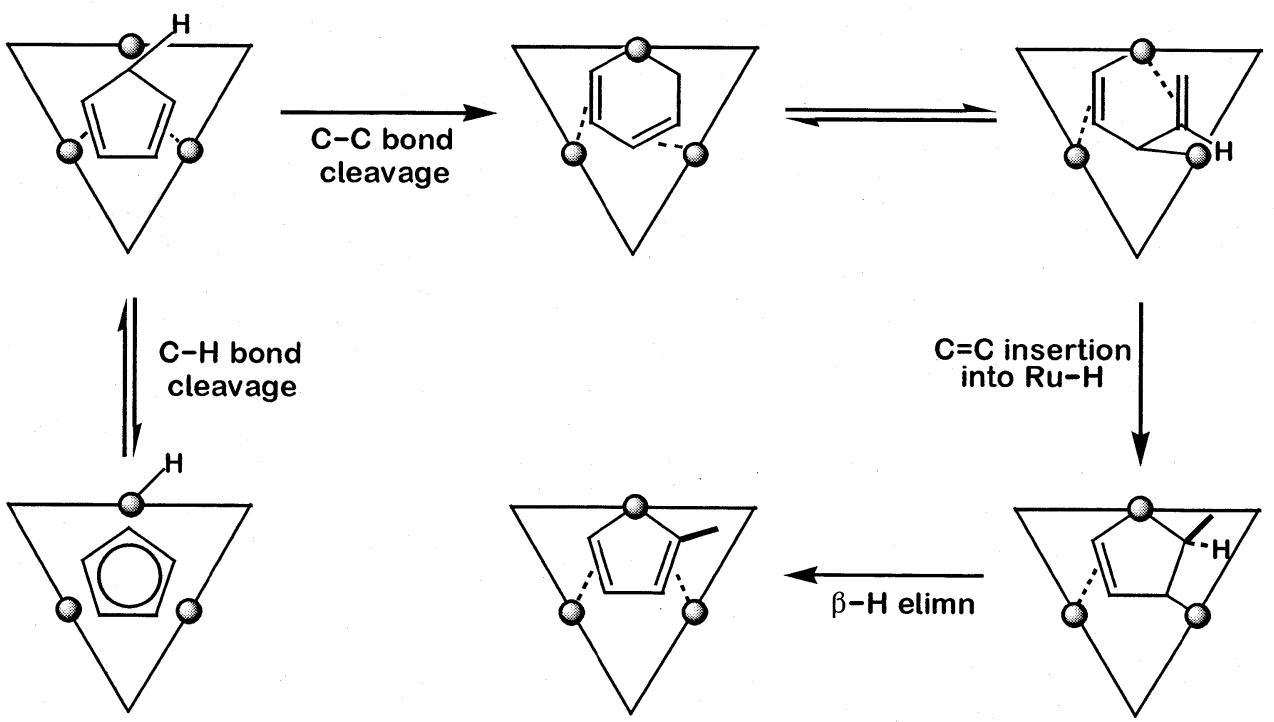

\section{Reaction of 1 with 1,3-Cyclohexadiene. Formation of a Trinuclear Ruthenium Complex with a Face-capping Benzene Ligand.}

The space of the triangular reaction site in $\mathbf{1}$ is large enough to accommodate a $\mathrm{C}_{6}$-ring compound. The reaction of 1 with 5 equiv of 1,3-cyclohexadiene in tetrahydrofuran at ambient temperature resulted in the quantitative formation of a facial benzene complex $(\mathrm{Cp} \text { 'Ru})_{3}(\mu-\mathrm{H})_{3}\left(\mu_{3^{-}}\right.$ $\left.\eta^{2}: \eta^{2}: \eta^{2}-\mathrm{C}_{6} \mathrm{H}_{6}\right)(6)$ via $\mathrm{C}-\mathrm{H}$ bond cleavage at the allylic carbon atoms (eq. 4).

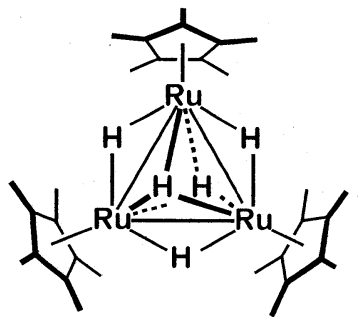

1

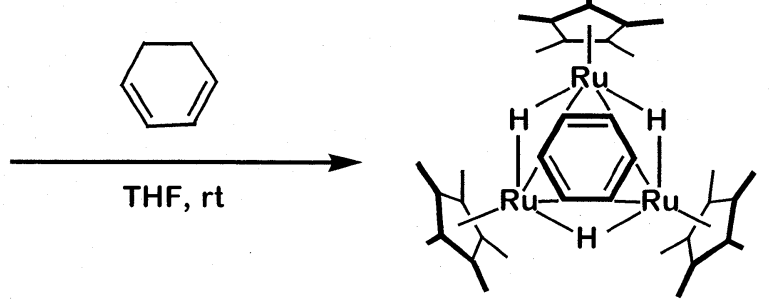

6

(eq. 4) 
The shifts of $\delta 2.43$ and 35.8 for the ${ }^{1} \mathrm{H}$ and ${ }^{13} \mathrm{C}$ NMR resonances for the coordinated benzene ligand, respectively, are much higher than those observed in the carbonyl clusters $\mathrm{Ru}_{3}(\mathrm{CO})_{9}\left(\mu_{3^{-}}\right.$ $\left.\eta^{2}: \eta^{2}: \eta^{2}-\mathrm{C}_{6} \mathrm{H}_{6}\right)\left(\delta_{\mathrm{H}} 4.56\right)$ (ref. 5) and $\mathrm{Os}_{3}(\mathrm{CO})_{9}\left(\mu_{3}-\eta^{2}: \eta^{2}: \eta^{2}-\mathrm{C}_{6} \mathrm{H}_{6}\right)\left(\delta_{\mathrm{H}} 4.42, \delta_{\mathrm{C}} 38.2\right)$ (ref. 6).

The $\mu_{3}-\eta^{2}: \eta^{2}: \eta^{2}$ coordination of the benzene ring was unequivocally confirmed by X-ray diffraction study (Fig. 3). Average "coordinated" and "uncoordinated" C-C distances (1.43(1) $\AA$ vs $1.43(1) \AA$ ) of $\mathrm{C}_{6} \mathrm{H}_{6}$ ligand in 6 are almost equal within experimental error.

The reaction of 1 with 1,3-cyclohexadiene to give 6 is first-order in both 1 and cyclohexadiene $\left(k_{\mathrm{obs}}\right.$ $=2.7(1) \times 10^{-3} \mathrm{~mol}^{-1} \mathrm{~s}^{-1}$ at $\left.66^{\circ} \mathrm{C}\right)$ with $\Delta \mathrm{H}^{\ddagger}=13.5(8)$ kcal $\mathrm{mol}^{-1}$ and $\Delta \mathrm{S}^{\ddagger}=-30.6(3) \mathrm{cal} \mathrm{mol}^{-1} \mathrm{~K}^{-1}$. The value of activation entropy is comparable to that for the reaction of 1 with cyclopentadiene as mentioned above. The negative large value of $\Delta S^{\ddagger}$ and the relatively small value of $\Delta \mathrm{H}^{\ddagger}$ indicate that fitting into the size and shape between the substrate and the reaction surrounded by the three $\mathrm{C}_{5} \mathrm{Me}_{5}$ groups is

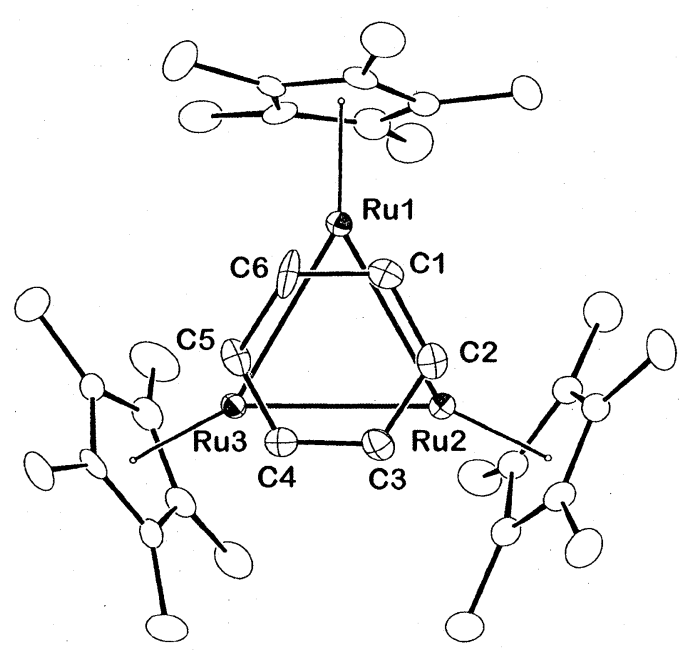

Figure 3. ORTEP drawing of 6 essential for the progress of the reaction.

In an attempt to observe intermediates by NMR spectroscopy, the reaction was performed in an NMR tube at $0{ }^{\circ} \mathrm{C}$. Although there was no resonance signal except for those attributable to 1,6 , and $\mathrm{H}_{2}$, the reaction most likely proceeds via an intermediary $\mu_{3}-\eta^{2}: \eta^{2}$-cyclohexadiene complex. One plausible reaction mechanism for the reaction of 1 with cyclohexadiene leading to the $\mu_{3}-\eta^{2}: \eta^{2}$ cyclohexadiene complex 6 is illustrated in Scheme 3. In the present reaction, two of the three metal centers in $\mathbf{1}$ act as coordination sites and the third metal plays the role of an activation site to cleave an allylic $\mathrm{C}-\mathrm{H}$ bond as observed in the reaction of $\mathbf{1}$ with butadiene or isoprene.

\section{Scheme 3}

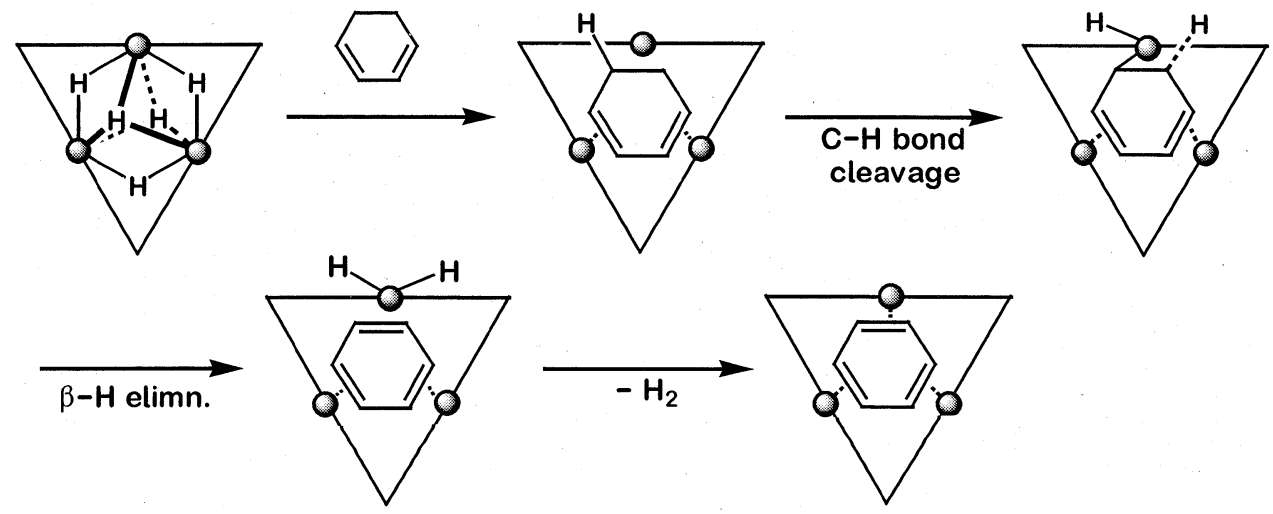


In the trimetallic reaction site of the triruthenium pentahydride $\mathbf{1}$, conjugated dienes of the appropriate size and shape can be effectively activated due to the concerted action of the three metal centers. The reaction of 1 with 1,4-cyclohexadiene or 1,3-cycloheptadiene, however, requires heating at $60-100{ }^{\circ} \mathrm{C}$ to complete because the orientation of two carbon-carbon double bonds or the ring size of the substrate is not suitable for the coordination to the $\mathrm{Ru}_{3}$ site.

\section{References}

(1) (a) Sponsler, M. B.; Weiller, B. H.; Stoutland, P. O.; Bergman, R. G. J. Am. Chem. Soc. 1989, 111, 6841. (b) Buchanan, J. M.; Stryker, J. M.; Bergman, R. G. J. Am. Chem. Soc. 1986, 108, 1537. (c) Periana,R. A.; Bergman, R. G. J. Am. Chem. Soc. 1986, 108, 7332. (d) Jones, W. D.; Feher, F. J. J. Am. Chem. Soc. 1986, 108, 4814. (e) Baker, M. V.; Field, L. D. J. Am. Chem. Soc. 1986, 108, 7433. (f) Baker, M. V.; Field, L. D. J. Am. Chem. Soc. 1986, 108, 7436. (g) Crabtree, R. H.; Parnell, C. P. Organometallics 1984, 3, 1727 . (h) Crabtree, R. H.; Mihelcic, J. M.; Quirk, J. M. J. Am. Chem. Soc. 1979, 101, 7738. (i) Crabtree, R. H.; Mellea, M. F.; Mihelcic, J. M.; Quirk, J. M. J. Am. Chem. Soc. 1982, 104, 107. (j) Crabtree, R. H.; Holt, E. N.; Lavin, M.; Morehouse, S. M. Inorg. Chem. 1985, 24, 1986. (k) Crabtree, R. H.; Dion, R. P. J. Chem. Soc., Chem. Commun. 1984, 1260. (l) Baudry, D.; Ephritikhine, M.; Felkin, H.; Holmes-Smith, R. J. Chem. Soc., Chem. Commun. 1983, 788. (m) Baudry, D.; Ephritikhine, M.; Felkin, H. J. Chem. Soc., Chem. Commun. 1980, 1243. (n) Baudry, D.; Ephritikhine, M.; Felkin, H. J. Chem. Soc., Chem. Commun. 1982, 606. (o) Baudry, D.; Ephritikhine, M.; Felkin, H. J. Organomet. Chem. 1982, 224, 363. (p) Felkin, H.; Fillebeen-Khan, T.; Holmes-Smith, R.; Yingrui, L. Tetrahedron Lett. 1985, 26, 1999.

(2) (a) Suzuki, H.; Omori, H.; Lee, D. H.; Yoshida, Y.; Moro-oka, Y. Organometallics 1988, 7, 2243.

(b) Suzuki, H.; Omori, H.; Moro-oka, Y. Organometallics 1988, 7, $2579 . \quad$ (c) Omori, H.; Suzuki, H.; Moro-oka, Y. Organometallics 1989, 8, 1576. (d) Omori, H.; Suzuki, H.; Moro-oka, Y. Organometallics 1989, 8, $2270 . \quad$ (e) Suzuki, H.; Kakigano, T.; Igarashi, M.; Tanaka, M.; Morooka, Y. J. Chem. Soc., Chem. Commun. 1991, 283. (f) Omori, H.; Suzuki, H.; Kakigano, T.; Moro-oka, Y. Organometallics 1992, 11, 989. (g) Suzuki, H.; Takao, T.; Tanaka, M.; Moro-oka, Y. J. Chem. Soc., Chem. Commun. 1992, 476. (h) Suzuki, H.; Omori, H.; Lee, D. H.; Yoshida, Y.; Fukushima, M.; Tanaka, M.; Moro-oka, Y. Organometallics 1994, 13, 1129. (i) Takao, T.; Suzuki, H.; Tanaka, M. Organometallics 1994, 13, 2554. (j) Takao, T.; Yoshida, S.; Suzuki, H.; Tanaka, M. Organometallics 1995, 14, 3855 . (k) Tada, K.; Oishi, M.; Suzuki, H.; Tanaka, M. Organometallics 1996, 15, 2422.

(3) (a) Suzuki, H.; Takaya, Y.; Takemori, T.; Tanaka, M. J. Am. Chem. Soc. 1994, 116, $10779 . \quad$ (b) Takemori, T.; Suzuki, H.; Tanaka, M. Organometallics 1996, 15, 4364. (c) Inagaki, A.; Takaya, Y.; Takemori, T.; Suzuki, H.; Tanaka, M.; Haga, M. J. Am. Chem. Soc. 1997, 119, 625. (d) Matsubara, K.; Okamura, R.; Tanaka, M.; Suzuki, H. J. Am. Chem. Soc. 1998, 120, $1108 . \quad$ (e) Matsubara, K.; Inagaki, A.; Tanaka, M.; Suzuki, H. J. Am. Chem. Soc. in press. (f) Inagaki, A.; Takemori, T.; Tanaka, M.; Suzuki, H. Angew. Chem., Int. Ed. Engl. in press.

(4) (a) Erker, G.; Fromberg, W.; Angermund, K.; Schlund, R.; Kruger, C. J. Chem. Soc., Chem. 
Commun. 1986, 1629. (b) Kryspin, I.-H.; Gleiter, R.; Kruger, C.; Zwettler, R.; Erker, G. Organometallics 1990, 9, 517. (c) Lemke, F. R.; Szalda, D. J.; Bullock, R. M. J. Am. Chem. Soc. 1991, 113, 8466. (d) He, Z.; Plasseraud, L.; Moldes, I.; Dahan, F.; Neibecker, D.; Etienne, M.; Mathieu, R. Angew. Chem., Int. Ed. Engl. 1995, 34, 916 . (e) Brookhart, M.; Green, M. L. H. J. Organomet. Chem. 1983, 250, 395.

(5) Johnson, B. F. G.; Lewis, J.; Martinelli, M.; Wright, A. H.; Braga, D.; Grepioni, F. J. Chem. Soc., Chem. Commun. 1990, 364.

(6) Gallop, M. A.; Gomez-Sal, M. P.; Housecroft, C. E.; Johnson, B. F. G.; Lewis, J.; Owen, S. M.; Raithby, P. R.; Wright, A. H. J. Am. Chem. Soc. 1992, 114, 2502.

(Received July 6, 1999) 